\title{
Physico-chemical Properties of Solutions of Lithium Bis(fluorosulfonyl)imide (LiFSI) in Dimethyl Carbonate, Ethylene Carbonate, and Propylene Carbonate
}

\author{
Johannes Neuhaus, Erik von Harbou ${ }^{1}$, Hans Hasse \\ Laboratory of Engineering Thermodynamics (LTD), University of Kaiserslautern, \\ Erwin-Schrödinger Str. 44, D-67663 Kaiserslautern, Germany
}

\begin{abstract}
Battery performance strongly depends on the choice of the electrolyte-solvent system. Lithium bis(fluorosulfonyl)imide (LiFSI) is a highly interesting novel electrolyte. Information on physico-chemical properties of solutions of LiFSI, however, is scarce. Therefore, the density, shear viscosity, and electrical conductivity of solutions of LiFSI in three pure solvents that are interesting for battery applications: dimethyl carbonate (DMC), ethylene carbonate (EC), and propylene carbonate (PC), were studied experimentally at temperatures between $273 \mathrm{~K}$ and $333 \mathrm{~K}$ at 1 bar and concentrations of LiFSI up to $0.45 \mathrm{~mol} \mathrm{~mol}^{-1}$ in the present work. Empirical correlations of the experimental data are provided. The comparison of the data of this work with the corresponding $\mathrm{LiPF}_{6}$ data underpins the attractiveness of LiFSI as an electrolyte in lithium ion batteries. Keywords: lithium bis(fluorosulfonyl)imide (LiFSI), electrical conductivity, density, shear viscosity, lithium ion battery, electrolyte solution
\end{abstract}

\footnotetext{
${ }^{1}$ Author to whom correspondence should be addressed. Electronic mail: erik.vonharbou@mv.uni-kl.de. Telephone: +49-631/205-5585. Fax: +49-631/205-3835.
}

Preprint submitted to Journal of Power Sources

May 14, 2018 


\section{Introduction}

Lithium-ion batteries ( $\mathrm{LiB})$ are well established for the storage of electrical energy, and there is a continuously growing demand for both smaller and more powerful LiB [1-3]. The performance of the batteries depends on many factors, among which the choice of the electrolyte-solvent system is one of the most important $[4-10]$.

Since its introduction to market in the 1990's, lithium hexafluorophosphate $\left(\mathrm{LiPF}_{6}\right)$ is the most common electrolyte in LiB. One of the strong points of $\mathrm{LiPF}_{6}$ is its high electrical conductivity in organic solvents. A promising new electrolyte for $\mathrm{LiB}$ is lithium bis(fluorosulfonyl)imide (LiFSI). It has an even higher electrical conductivity in organic solvents than $\mathrm{LiPF}_{6}$, and has other advantages like a better stability regarding hydrolysis and lower aluminium corrosion $[11-16]$.

15

Despite the high interest in LiFSI, little is known up to now on the physicochemical properties of its solutions in the commonly used solvents: dimethyl carbonate (DMC), ethylene carbonate (EC), and propylene carbonate (PC). In practice, often solvent mixtures are used in LiB. The data on LiFSI in the single solvents that are presented here is needed as a prerequisite for modeling solutions in solvent mixtures. Tab. 1 gives an overview of literature data on physico-chemical properties of solutions of LiFSI. 
Tab. 1 shows that the data on physico-chemical properties of solutions of

LiFSI in DMC, EC, and PC, are spotty. Therefore, a systematic experimental study on the density, shear viscosity, and electrical conductivity of solutions of LiFSI in these solvents was carried out in the present work. The three properties were determined for mole fractions of LiFSI up to $0.45 \mathrm{~mol} \mathrm{~mol}^{-1}$, corresponding to a molarity of about $5.5 \mathrm{M}$, and temperatures between $273 \mathrm{~K}$ and $333 \mathrm{~K}$.

Empirical correlations of the new experimental data are provided that enable a systematic comparison of the present data of LiFSI with data of $\mathrm{LiPF}_{6}$ available in the literature.

Table 1: Overview of literature data on physico-chemical properties of solutions of LiFSI in organic solvents.

\begin{tabular}{ccccc}
\hline \hline Solvent (mixture) & $c_{\text {Lifsi }} / \mathrm{M}$ & $T / \mathrm{K}$ & Properties & Reference \\
\hline ACN & $0.4-4.0$ & $233-373$ & $\sigma, \eta, \rho$ & Han et al. [12] \\
DMC & $0.5-5.5$ & 303 & $\sigma, \eta, \rho$ & Wang et al. [16] \\
DMC & $0.1-5.0$ & $223-323$ & $\sigma$ & Li et al. [17] \\
DME & $1.0-5.0$ & 298 & $\sigma$ & Qian et al. [18] \\
EC & $0.6-5.7$ & 303 & $\sigma, \eta, \rho$ & Wang et al. [16] \\
DEC-EC $(7: 3)$ & 1.0 & $253-293$ & $\sigma, \eta$ & Takekawa et al. [19] \\
DMC-EC $(1: 1,9: 1)$ & 1.0 & 298 & $\sigma, \eta$ & Uchida and Ishikawa [20] \\
DMC-EMC $(3: 7)$ & 1.0 & $223-323$ & $\sigma$ & Li et al. [17] \\
DMC-EC (1:1) & $0.6-5.3$ & 303 & $\sigma, \eta, \rho$ & Wang et al. [16] \\
EMC-EC (7:3) & 1.0 & $253-333$ & $\sigma, \eta$ & Han et al. [11] \\
DMC-EMC-EC (2:3:5) & 1.0 & $253-323$ & $\sigma$ & Li et al. [17] \\
\hline$\sigma$ electrical conductivity, $\rho$ density, $\eta$ shear viscosity; ${ }^{*}:$ volume ratio. \\
Abbr.: ACN: acetonitrile; DME: 1,2-dimethoxyethane; DEC: diethyl carbonate; \\
DMC: dimethyl carbonate; EMC: ethyl-methyl carbonate; EC: ethylene carbonate. \\
\hline \hline
\end{tabular}




\section{Experimental Section}

35

2.1. Chemicals

Lithium bis(fluorosulfonyl)imide (LiFSI, $\geq 0.999 \mathrm{~g} \mathrm{~g}^{-1}$ ) was supplied by Budan Process UG. Dimethyl carbonate (anhydrous, $\geq 0.999 \mathrm{~g} \mathrm{~g}^{-1}$ ), ethylene carbonate (anhydrous, $0.99 \mathrm{~g} \mathrm{~g}^{-1}$ ), and propylene carbonate (anhydrous, $0.997 \mathrm{~g} \mathrm{~g}^{-1}$ ) were purchased from Sigma Aldrich. All chemicals were used as 40 received. The water content of the pure components was determined by coulometric Karl-Fischer titration (Metrohm $831 \mathrm{KF}$ coulometer) and were found to be below $50 \cdot 10^{-6} \mathrm{~g} \mathrm{~g}^{-1}$ for all solvents, and below $30 \cdot 10^{-6} \mathrm{~g} \mathrm{~g}^{-1}$ for LiFSI.

All chemicals were handled in an inert gas glove box (GS Glovebox Tech45 nik) that maintained an nitrogen atmosphere with a water content of less than $2 \cdot 10^{-6} \mathrm{~g} \mathrm{~g}^{-1}$. A laboratory balance (Mettler-Toledo AG204) with an accuracy of $\pm 0.0001 \mathrm{~g}$ according to the calibration protocol was used for the gravimetrical sample preparation. The total mass of each prepared sample was larger than $30 \mathrm{~g}$. The samples were hermetically sealed in $40 \mathrm{ml}$ glass vials. The uncertainty of the mass fraction of LiFSI is estimated to be $\pm 0.00015 \mathrm{~g} \mathrm{~g}^{-1}$.

Some relevant physico-chemical properties of the employed solvents and electrolytes are shown in Tab. 2, wherein $M$ is the molar mass, $T_{\mathrm{nmp}}$ and $T_{\mathrm{nbp}}$ are the normal melting point and the normal boiling point, respectively, $\rho$ is the density, $\eta$ is the shear viscosity, $D$ is the self-diffusion coefficient and $\epsilon$ is the dielectric constant. 
Table 2: Overview of some pure component physico-chemical properties. The numbers for $\rho, \eta$, and $\epsilon$ for $\mathrm{DMC}, \mathrm{EC}$, and $\mathrm{PC}$ refer to the liquid state at $313.15 \mathrm{~K}$ and ambient pressure.

\begin{tabular}{|c|c|c|c|c|c|}
\hline Property & $\overline{\overline{D M C}}$ & $\overline{\mathrm{EC}}$ & $\overline{\mathrm{PC}}$ & 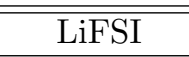 & $\mathrm{LiPF}_{6}$ \\
\hline & $\mathrm{C}_{3} \mathrm{H}_{6} \mathrm{O}_{3}$ & $\mathrm{C}_{3} \mathrm{H}_{4} \mathrm{O}_{3}$ & $\mathrm{C}_{4} \mathrm{H}_{6} \mathrm{O}_{3}$ & $\mathrm{~F}_{2} \mathrm{LiNO}_{4} \mathrm{~S}_{2}$ & $\mathrm{LiPF}_{6}$ \\
\hline$M / \mathrm{g} \mathrm{mol}^{-1}$ & 90.1 & 88.1 & 102.1 & 187.1 & 151.9 \\
\hline$T_{\mathrm{nmp}} / \mathrm{K}$ & $278.2^{a}$ & $311.2^{a}$ & $220.3^{a}$ & $418.2^{k}$ & $473.2^{l}$ \\
\hline$T_{\mathrm{nbp}} / \mathrm{K}$ & $363.15^{b}$ & $517.15^{b}$ & $513.15^{b}$ & & \\
\hline$\rho / \mathrm{g} \mathrm{cm}^{-3}$ & $1.0434^{c}$ & $1.3216^{d}$ & $1.1893^{e}$ & & \\
\hline$\eta / \mathrm{mPas}$ & $0.4880^{f}$ & $1.9000^{g}$ & $1.9120^{e}$ & & \\
\hline$D / 10^{-9} \mathrm{~m} \mathrm{~s}^{-2}$ & $26.0^{h, *}$ & $8.0^{h}$ & $5.8^{h, *}$ & & \\
\hline$\epsilon$ & $3.2^{i}$ & $89.7^{j}$ & $61.4^{j}$ & & \\
\hline $\begin{array}{l}\text { References: }{ }^{a}[21 \\
k^{k}[11] .{ }^{l}[31] .{ }^{*} \mathrm{M}\end{array}$ & $\begin{array}{l}{[22] .{ }^{c}[23} \\
\text { ured at } 3\end{array}$ & $\begin{array}{l}24] .{ }^{e}[25] \\
\mathrm{K} .\end{array}$ & 26]. ${ }^{g}[27]$. & [28]. ${ }^{i}[29] .{ }^{j}$ & \\
\hline
\end{tabular}

\subsection{Measurements}

\subsubsection{Density and Shear Viscosity}

For the measurements of the density and the shear viscosity a combined instrument of Anton Paar (SVM 3000) was used. In this instrument, the density is measured with the vibrating tube technique and the shear viscosity is measured by a Stabinger viscosimeter. The measurements of the density were conducted according to the ASTM method D4052 and the measurements of the dynamic viscosity according to the ASTM method D7042. Before and after each set of the measurements the apparatus was cleaned with toluene, water and ethanol and flushed with dry nitrogen. The measurements were carried out at ambient 
pressure.

The apparatus was calibrated with a calibration standard provided by the manufacturer. Three other standards purchased from Paragon Scientific Ltd. (D5, N14, and N100) were used for testing. Deviations between the reported value and the own measurements were found to be below $0.05 \%$ for the density and below $0.7 \%$ for the viscosity in the studied temperature range which was between $273 \mathrm{~K}$ and $333 \mathrm{~K}$. All measurements of the present work were repeated three times for a given temperature and sample composition. Thus, the results listed in this work are the arithmetic mean of the three measurements. The relative standard deviation of the three measurements was $\leq 0.15 \%$ for the density and the viscosity. Therefore, we conclude that the uncertainty of the density data reported here is about $\pm 0.15 \%$ and that of the viscosity is about $\pm 0.7 \%$. The temperature was measured with a built-in thermometer for which the manufacturer reports an uncertainty of $\pm 0.05 \mathrm{~K}$. This may be to optimistic. Our estimate for the uncertainty is $\pm 0.1 \mathrm{~K}$.

\subsubsection{Electrical Conductivity}

A conductivity meter was used (Mettler-Toledo Seven Multi equipped with an inLab 720 probe) for the measurements of the electrical conductivity. The measurements were carried out at ambient pressure. The conductivity meter was calibrated at $298.15 \mathrm{~K}$ using aqueous solutions of $\mathrm{NaCl}$ with a maximum concentration of $\mathrm{NaCl}$ of $0.3 \mathrm{~mol} \mathrm{l}^{-1}$. The reference data were taken from 90 Wadsworth [32]. The maximum relative deviation of an individual result from 
the calibration curve was $0.8 \%$. That number is taken for the relative uncertainty of the measurement of the electrical conductivity. The temperature was controlled using a thermostat (Julabo F32 HE) and measured with the built-in thermometer provided by the instrument's supplier, which was calibrated in our laboratory using a certified standard. The uncertainty of the temperature measurement was $\pm 0.1 \mathrm{~K}$. Before and after each set of measurements the apparatus was cleaned with toluene, water and ethanol and flushed with dry nitrogen.

\section{Correlations}

\subsection{Density}

100

In previous works of our group [33, 34], it was found that the specific density of electrolyte solutions is a linear function of the mole fraction of cations if the concentration of cations in the solution is small $\left(x_{\mathrm{c}^{+}} \leq 0.05 \mathrm{~mol} \mathrm{~mol}{ }^{-1}\right)$. Thus, the density of the electrolyte solution is described in this work as a function of the mole fraction of $\mathrm{Li}^{+}$. However, as the maximum concentration of $\mathrm{Li}^{+}$in the solution was much higher in this work $\left(x_{\mathrm{Li}^{+}} \leq 0.45 \mathrm{~mol} \mathrm{~mol}^{-1}\right)$, a quadratic term was added resulting in the correlation given in Eq. (1).

$$
\left(\frac{\rho}{\mathrm{g} \mathrm{cm}^{-3}}\right)=A_{0, k}+A_{1, k} x_{\mathrm{Li}^{+}}+A_{2, k} x_{\mathrm{Li}^{+}}^{2}
$$

$x_{\mathrm{Li}^{+}}$is the true mole fraction of $\mathrm{Li}^{+}$-ions

$$
x_{\mathrm{Li}^{+}}=\frac{n_{\mathrm{Li}^{+}}}{n_{\mathrm{Li}^{+}}+n_{\mathrm{FSI}^{-}}+n_{k}}
$$


wherein $n_{i}$ is the mole number of species $i$. The correlations of the present work are established assuming that LiFSI is always dissociated in the solutions. They remain applicable independent of the physical validity of that assumption. The $A_{0, k}$ is the density of the pure solvent $k$ (with $k=\mathrm{DMC}, \mathrm{EC}, \mathrm{PC}$ ). The temperature dependence of the parameters $A_{i, k}$ is described by:

$$
A_{i, k}=a_{i, k}+b_{i, k}\left(\frac{T}{T_{0}}\right)
$$

with $i=(0,1,2)$ and $T_{0}=273.15 \mathrm{~K} . a_{i, k}$ and $b_{i, k}$ are adjustable parameters.

(cf. Eq. (1)) and the molar mass of the mixture $M$ :

$$
v=\frac{M}{\rho}
$$

Further, the partial molar volume of LiFSI in solution can be calculated from Eq. (5)

$$
v_{\mathrm{LiFSI}}=\left(\frac{\partial V}{\partial n_{\mathrm{LiFSI}}}\right)_{T, p, n_{k}}
$$

where $n_{\mathrm{LiFSI}}$ is the apparent mole number of LiFSI and $V$ is the volume of 


\subsection{Shear viscosity}

The dependence of the dynamic viscosity $\eta$ of the studied electrolyte solutions on the composition of the solution and on the temperature is described by Eq. (6):

$$
\ln \left(\frac{\eta}{\mathrm{mPa} \mathrm{s}}\right)=A_{0, k}+A_{1, k} x_{\mathrm{LiFSI}}+A_{2, k} x_{\mathrm{LiFSI}}^{2}
$$
are empirical temperature dependent functions

$$
A_{i, k}=a_{i, k}+\frac{b_{i, k}}{\left(\frac{T}{T_{0}}\right)}+\frac{c_{i, k}}{\left(\frac{T}{T_{0}}\right)^{2}}
$$

with $i=(0,1,2), k=\mathrm{DMC}, \mathrm{EC}, \mathrm{PC})$ and $T_{0}=273.15 \mathrm{~K}$. Due to the strong temperature dependence (see Section 4.2) a quadratic functions was used. $a_{i, k}, b_{i, k}$ and $c_{i, k}$ are adjustable parameters.

\subsection{Electrical conductivity}

For correlating the electrical conductivity of the studied electrolyte solutions, we found Eq. (8) to be suitable.

$$
\left(\frac{\sigma}{\mathrm{mS} \mathrm{cm}^{-1}}\right)=A_{0, k}+A_{1, k} X_{\mathrm{LiFSI}}+A_{2, k} X_{\mathrm{LiFSI}}^{2}+A_{3, k} X_{\mathrm{LiFSI}}^{3}+A_{4, k} X_{\mathrm{LiFSI}}^{4}
$$


where $X_{\mathrm{LiFSI}}$ is the apparent molar loading of the pure solvent $k$ with LiFSI.

$$
X_{\mathrm{LiFSI}}=\frac{n_{\mathrm{LiFSI}}}{n_{k}}
$$

The $A_{i, k}$ are empirical temperature dependent functions

$$
A_{i, k}=a_{i, k}+b_{i, k}\left(\frac{T}{T_{0}}\right)
$$

with $i=(0, \ldots, 4)$ and $T_{0}=273.15 \mathrm{~K} . a_{i, k}$ and $b_{i, k}$ are adjustable parameters.

\subsection{Parameter estimation}

All adjustable parameters in the equations listed above were estimated by the method of least squares. The sum of the squared relative errors between the experimental data and the correlation $e_{j}=\left(z_{j}^{\text {corr }}-z_{i}^{\exp }\right) / z_{i}^{\exp }$ was employed as objective functions for all properties $z_{i}$. The optimization procedure was carried out in Mathworks Matlab 2016b using the solver lsqnonlin.

\section{Results and Discussion}

\subsection{Density}

The experimental data obtained in the present work for the density of solutions of LiFSI in the pure solvents DMC, EC, and PC are reported in the Appendix in Tables A1, A2, and A3, respectively. The parameters of the correlation of that data (cf. Section 3.4) are reported in the Appendix in Tab. B1. 
Fig. 1 depicts the density of the studied mixtures as a function of temperature and mole fraction of $\mathrm{Li}^{+}$-ions. The experimental data as well as the correlation are shown. The correlation describes the experimental data within the experimental uncertainty. The dependence of the density on the mole fraction of $\mathrm{Li}^{+}$-ions and the temperature is almost linear for all studied solvents. Still, for PC a slight deviation from linearity is visible. Fig. 1 also shows that the agreement between the correlation and the experimental results is excellent.

Fig. 2 depicts the molar volume of the studied mixtures as a function of temperature and mole fraction of LiFSI. The dependence of the molar volume on the temperature is linear in the studied range for all systems. The dependence of the molar volume on the mole fraction of LiFSI at constant temperature is found to be nearly linear for the solvent EC. In contrast, it is non-linear for the solvents PC and DMC. The non-linearity is strong for DMC for which a minimum of the molar volume is clearly observable in Fig. 2 for all studied temperatures, at a mole fraction of LiFSI of about $0.2 \mathrm{~mol} \mathrm{~mol}^{-1}$.

165

Fig. 3 shows the partial molar volume of LiFSI which was calculated from the correlation of density (cf. Equations (1), (4), and (5)), as a function of the mole fraction of LiFSI at $333 \mathrm{~K}$ for all solvents. The trends shown in Fig. 3 are similar for other temperatures. Obviously, the partial molar volume of LiFSI 170 is always positive for all studied systems. The partial molar volume at infinite dilution $v_{\mathrm{LiFSI}}^{\infty}$ in $(\mathrm{DMC}, \mathrm{EC}, \mathrm{PC})$ is $(65.3,85.1,89.2) \mathrm{cm}^{3} \mathrm{~mol}^{-1}$. The mole 

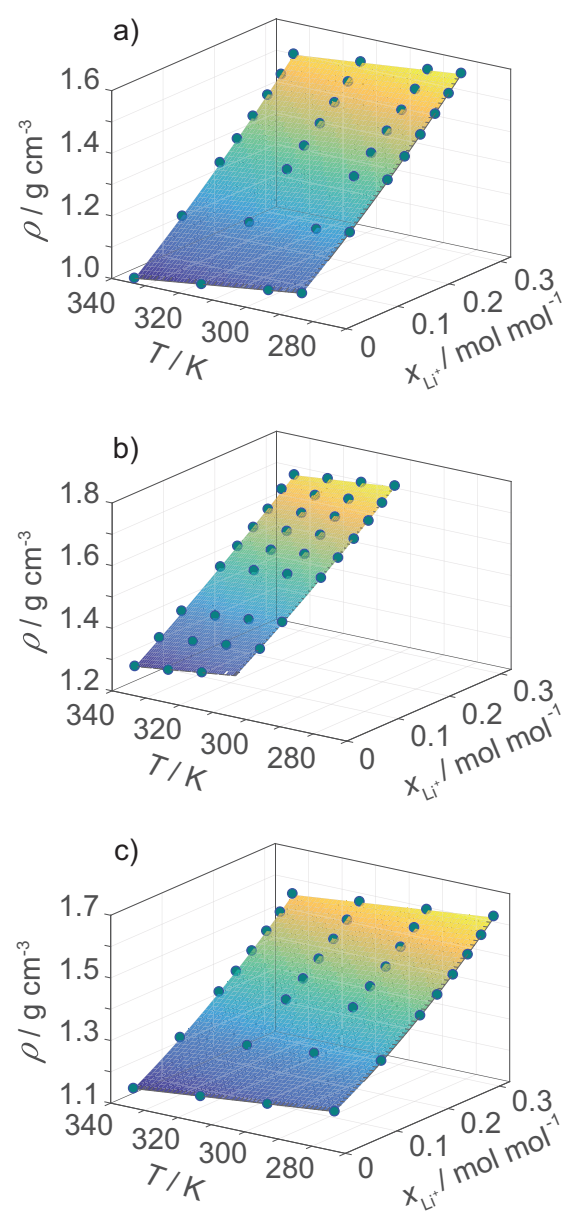

Figure 1: Specific density of solutions of LiFSI in a) DMC, b) EC, and c) $\mathrm{PC}$ as a function of the mole fraction of $\mathrm{Li}^{+}$-ions and temperature. Symbols: experimental data. Surface: correlation fitted to the experimental data, cf. Eq. (1). 

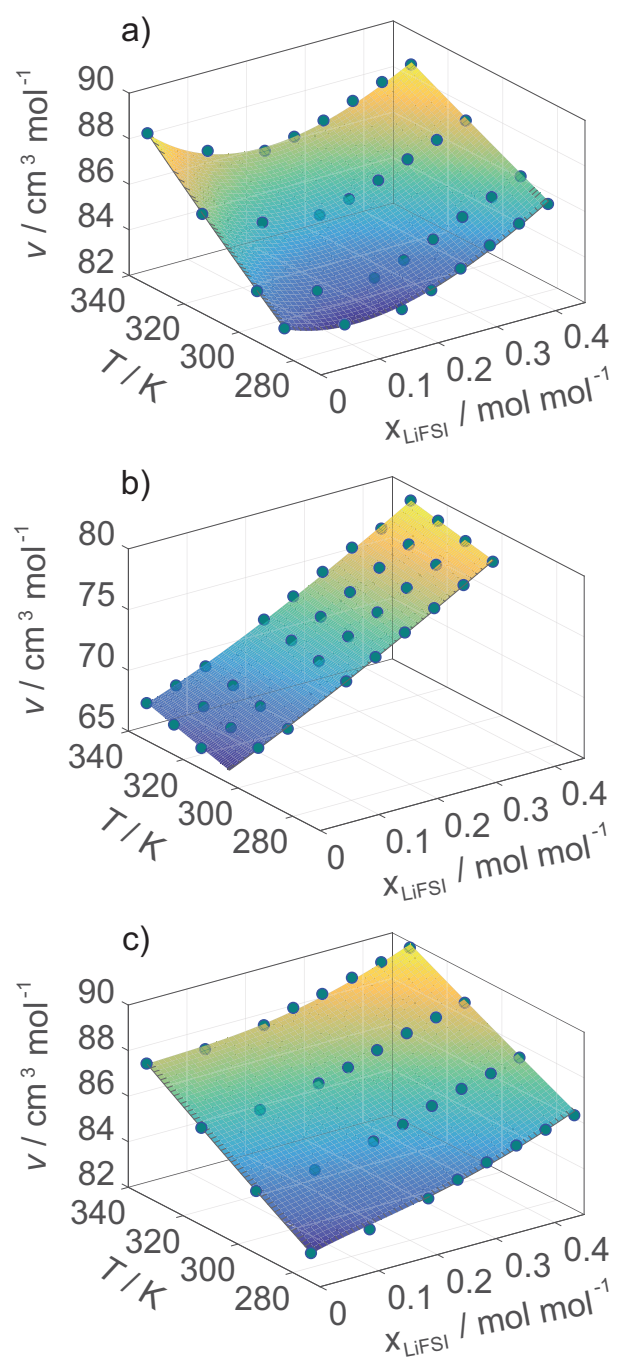

Figure 2: Molar volume of solutions of LiFSI in a) DMC, b) EC, and c) PC as a function of the mole fraction of LiFSI and temperature. Symbols: experimental data. Surface: correlation fitted to the experimental data, cf. Eq (1) and (4). 


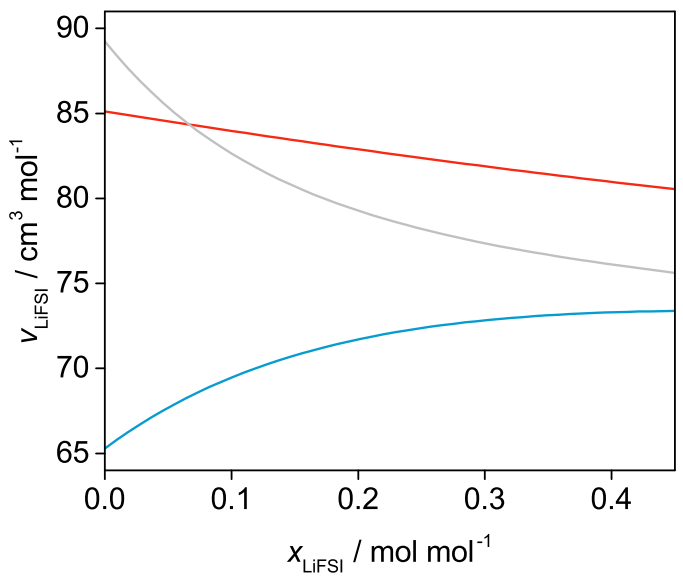

Figure 3: Partial molar volume of LiFSI in solutions of LiFSI in DMC (blue), EC (red), and PC (grey) as a function of the mole fraction of LiFSI at $333 \mathrm{~K}$.

fraction of LiFSI has a strong influence on the partial molar volume of LiFSI for DMC and PC, whereas it is less important for EC.

The addition of LiFSI has an influence on the structure of the fluid for all solvents. Quantum chemical calculations and molecular dynamics simulations indicate that the $\mathrm{Li}^{+}$-ion and carbonate molecules tend to form complexes with a maximal coordination number of 4 . Complexes with higher coordination numbers may be possible geometrically but are reported to be unfavorable $[22,35-$ 39]. The size of the $\mathrm{Li}^{+}-[\mathrm{DMC} / \mathrm{EC} / \mathrm{PC}]_{4}$ complexes is directly correlated with the size of the carbonate solvent molecules. Thus, the following relation holds:

$$
\mathrm{Li}^{+}[\mathrm{PC}]_{4}>\mathrm{Li}^{+}[\mathrm{EC}]_{4}>\mathrm{Li}^{+}[\mathrm{DMC}]_{4}
$$


This relation is confirmed by the numbers of the partial molar volume of LiFSI at infinite dilution reported above. nar DMC and the cyclic EC and PC. The partial molar volume of LiFSI in DMC increases with increasing mole fraction of LiFSI, while it decreases for EC and PC. For all solvents the coordination number decreases with increasing mole fraction of LiFSI, starting from $n=4$ at infinite dilution. However, the volume of the complexes with $n<4$ compared to that with $n=4$ is different for the three solvents. It is smaller for the cyclic EC and PC, while it is larger for the planar DMC. This difference in the change in volume is a consequence of their geometric structure.

\subsection{Shear viscosity}

Fig. 4 depicts the viscosity of the studied mixtures as a function of the temperature and the mole fraction of LiFSI. The experimental data obtained in the present work for the viscosity of solutions of LiFSI in the solvents DMC, EC, and PC are reported in the Appendix in Tables A4, A5, and A6. The parameters of the correlation of that data (cf. Section 3.4) are reported in the Appendix in Tab. B2. The parameter estimation procedure reveals that the parameter $c_{0, k}$ $\left(k=\right.$ DMC,EC,PC) and the parameter $c_{2, \mathrm{EC}}(\mathrm{cf}$. Eq. 7$)$ are not significant and thus they are set to zero. The correlation describes the experimental data for LiFSI in solutions of (DMC, EC, PC) within an maximal absolute deviation of $(0.4,3,1.7) \mathrm{mPa}$ s. 
As expected, both the temperature and the concentration of LiFSI have a strong influence on the viscosity. Qualitatively, all studied systems show similar behavior, with a strong increase of the viscosity at low temperatures and high concentrations of LiFSI. The temperature dependence of the viscosity is more important in regions where the viscosity is high. For all temperatures and compositions of the electrolyte solutions $x_{\text {LiFSI }}>0 \mathrm{~mol} \mathrm{~mol}^{-1}$ reported here the following relation holds (cf. Supplementary Information Fig. S1):

$$
\eta_{\mathrm{DMC}}<\eta_{\mathrm{PC}}<\eta_{\mathrm{EC}}
$$

The increase in viscosity with increasing concentration of LiFSI can be explained by the strong ion-dipole coordination of the $\mathrm{Li}^{+}$-ions and the carbonate molecules that leads to large, poorly mobile complexes. Additionally, $\mathrm{FSI}^{-}$ contributes to the increase of the viscosity. At high salt concentrations, also ion-pairing can play a role. Similar findings have been reported before for solutions of $\mathrm{LiPF}_{6}[40,41]$. The size of the solvent molecules is important for the viscosity. Our findings show that the size effect dominates for the pure solvents $\left(\eta_{\mathrm{DMC}}<\eta_{\mathrm{EC}}<\eta_{\mathrm{PC}}\right)$. Interestingly, the viscosity of solutions of LiFSI in EC is higher than in PC (see Fig. S1 in the Supplementary Information), even though PC is slightly larger than EC. This observation may be attributable to the polarity of EC (cf. dielectric constants in Table 2), and the corresponding strong ion-dipole bond of the $\mathrm{Li}^{+}$-EC complexes. This is in line with the findings of 225 Arai et al. [42] in solution of $\mathrm{LiPF}_{6}$ in several carbonate solvents. 

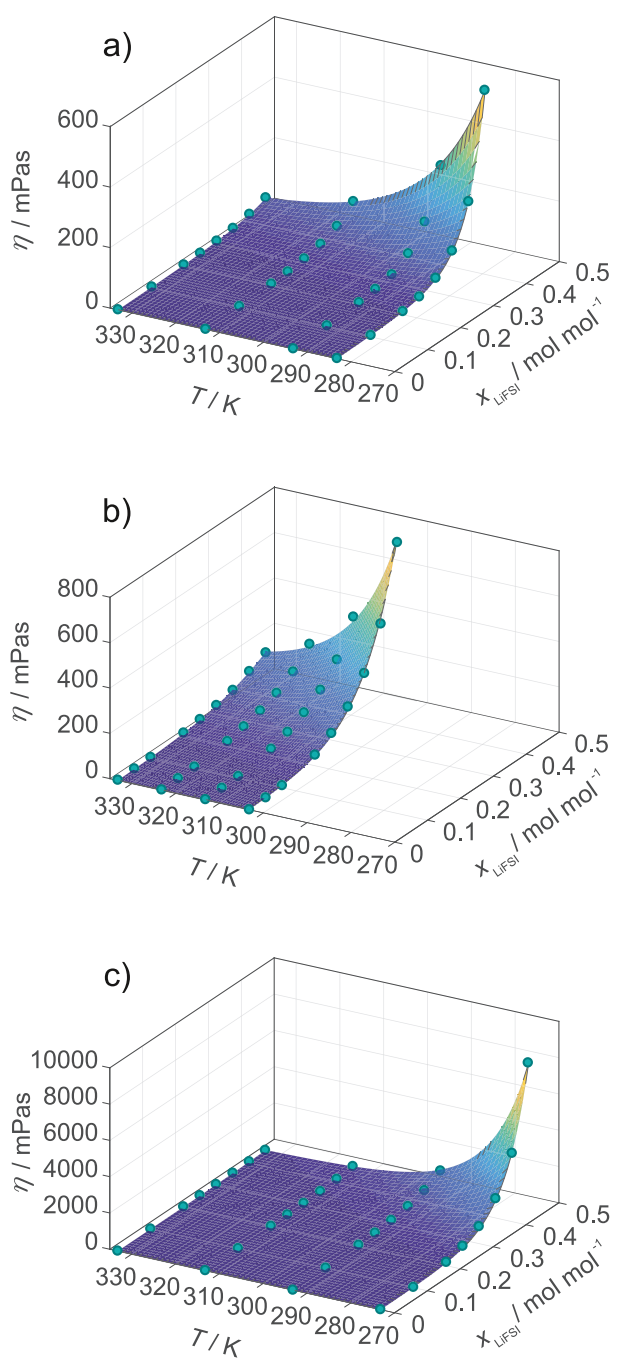

Figure 4: Shear viscosity of solutions of LiFSI in a) DMC, b) EC, and c) PC as a function of the mole fraction of LiFSI and temperature. Symbols: experimental data. Surface: correlation fitted to the experimental data, cf. Eq. (6). 


\subsection{Electrical conductivity}

The experimental data obtained in the present work for the electrical conductivity of solutions of LiFSI in the pure solvents DMC, EC, and PC are reported in the Appendix in Tables A7, A8, and A9. The parameters of the correlation of that data (cf. Section 3.4) are reported in Tab. B3 in the Appendix. The correlation describes the experimental data within a maximal absolute deviation of $(0.45,0.17,0.53) \mathrm{mS} \mathrm{cm}^{-1}$ for solutions of LiFSI in (DMC, EC, PC), which is slighty higher than the experimental relative uncertainty of $0.8 \%$.

Fig. 5 depicts the electrical conductivity $\sigma$ of the studied mixtures as a function of the temperature and the mole fraction of LiFSI. The electrical conductivity of the pure solvents is close to zero. With increasing mole fraction of LiFSI, the electrical conductivity increases first, goes through a maximum, and finally decreases for high mole fractions of LiFSI. That behavior is observed for all solvents and temperatures. Temperature and electrical conductivity are linearly related for all studied solutions. The maximal electrical conductivity of LiFSI solutions in (DMC, EC, PC) is $(16.2,15.5,12.3) \mathrm{mS} \mathrm{cm}^{-1}$ at $333 \mathrm{~K}$ and the corresponding mole fraction of LiFSI is $(0.17,0.10,0.08) \mathrm{mol} \mathrm{mol}^{-1}$. The electrical conductivity of the solutions of LiFSI in PC is always lower than that of solutions of LiFSI in EC at the same conditions. The comparison of the results for DMC with those for EC reveals that the increase in the electrical conductivity with increasing mole fraction of LiFSI is initially much stronger for the solvent EC. Furthermore, the maximum in the electrical conductivity is 
reached at lower concentrations of LiFSI for that solvent than for DMC.

Two counteracting effects influence the electrical conductivity in the studied solutions: with increasing mole fraction of LiFSI, more charge carriers are present in the solutions which leads to an increase in the electrical conductivity. However, with increasing mole fraction of LiFSI, the mobility of the charge carriers is hindered as a consequence of the increased viscosity (see previous section).

\subsection{Comparison of solutions of LiFSI and LiPF $_{6}$}

The comparison of the electrical conductivity of solutions of LiFSI and $\mathrm{LiPF}_{6}$ in the same solvent is presented here for all three solvents DMC, EC, and PC, as it is interesting both for practical and theoretical reasons. The data of $\mathrm{LiPF}_{6}$ are taken from experimental studies found in the literature. Unfortunately, only spotty data for $\mathrm{LiPF}_{6}$ is available in the literature, cf. Tab. 3 for a survey. As a direct comparison of the experimental data for $\mathrm{LiPF}_{6}$ and LiFSI at the same conditions is not possible, the experimental data for $\mathrm{LiPF}_{6}$ from the literature is compared to predictions of the correlation of the present work (cf. Section 3).

Table 3: Overview on experimental data taken from literature.

\begin{tabular}{cccc}
\hline \hline System & $x_{\mathrm{LiPF}_{6}} / \mathrm{mol} \mathrm{l}^{-1}$ & $T / \mathrm{K}$ & Reference \\
\hline $\mathrm{LiPF}_{6}-\mathrm{DMC}$ & $0.5-3.4,0.3-2.0$ & 298.15 & {$[43,44]$} \\
$\mathrm{LiPF}_{6}-\mathrm{EC}$ & 1.0 & $303.15-343.15$ & {$[45]$} \\
$\mathrm{LiPF}_{6}-\mathrm{PC}$ & $0.1-3.3,0.1-1.0$ & 298.15 & {$[25,46]$} \\
\hline \hline
\end{tabular}

Fig. 6 depicts the electrical conductivity of solutions of LiFSI and $\mathrm{LiPF}_{6}$ in DMC as a function of the molarity of the salt $c_{\text {salt }}$ at a constant temperature of 

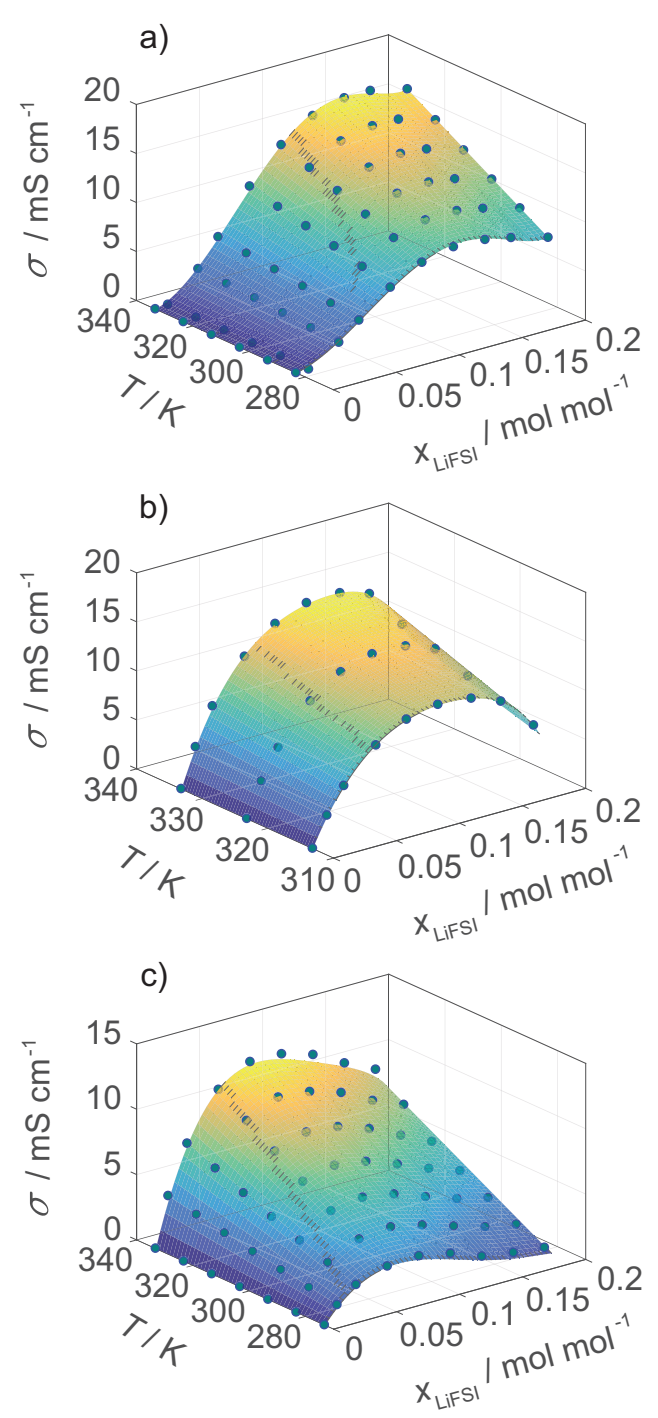

Figure 5: Electrical conductivity of solutions of LiFSI in a) DMC, b) EC, and c) PC as a function of the mole fraction of LiFSI and temperature. Symbols: experimental data. Surface: correlation fitted to the experimental data, cf. Eq (8). 


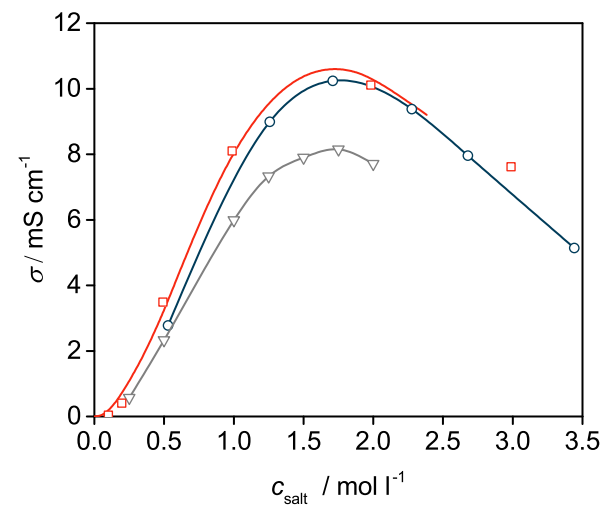

Figure 6: Electrical conductivity of solutions of LiFSI and $\mathrm{LiPF}_{6}$ in $\mathrm{DMC}$ as a function of the molarity of salt for a temperature of $298.15 \mathrm{~K}$. Red line: Regression for LiFSI-DMC (this work). Symbols: Experimental data for LiFSIDMC taken from [17] (red square), and experimental data for $\mathrm{LiPF}_{6}-\mathrm{DMC}$ taken from [43] (blue circle) and [44] (grey triangle) with lines as guide to the eye.

298 K. The data set for LiFSI from the Li et al. [17] is in good agreement with our regression for LiFSI-DMC. The two data sets for $\mathrm{LiPF}_{6}$ from the literature $[43,44]$, are found to be contradictory. Compared to the $\mathrm{LiPF}_{6}$ data from [43], LiFSI leads to a slightly higher electrical conductivity at constant molarity of salt, whereas the increase is important if the $\mathrm{LiPF}_{6}$ data of [44] is used as reference. The maximal value of the electrical conductivity is obtained at molarity of salt about $1.7 \mathrm{~mol} \mathrm{l}^{-1}$ for both salts. It is $10.7 \mathrm{mS} \mathrm{cm}^{-1}$ for LiFSI. For LiPF 6 , it is $10.2 \mathrm{mS} \mathrm{cm}{ }^{-1}$ according to [43] whereas [44] reports only $8.2 \mathrm{mS} \mathrm{cm}^{-1}$.

Results for the electrical conductivity of solutions of LiFSI and $\mathrm{LiPF}_{6}$ in EC are compared in Fig. 7 for a molarity of the salt of $1.0 \mathrm{~mol}^{-1}$ and temperatures between 313 and $333 \mathrm{~K}$. Using LiFSI instead of $\mathrm{LiPF}_{6}$ leads to a higher 


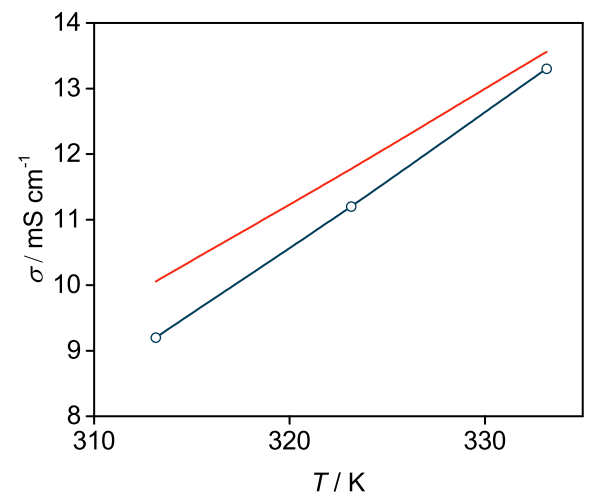

Figure 7: Electrical conductivity of solutions of LiFSI and $\mathrm{LiPF}_{6}$ in EC with a molarity of $c_{\text {salt }}=1.0 \mathrm{~mol} \mathrm{l}^{-1}$ as a function of temperature. Red line: Regression for LiFSI-EC (this work). Symbols: Experimental data for $\mathrm{LiPF}_{6^{-}}$ EC taken from [45] (blue) with line as guide to the eye.

electrical conductivity in the entire range depicted in Fig. 7. The relative differences are about $10 \%$ for the lowest and $3 \%$ for the highest studied temperature.

Fig. 8 depicts the electrical conductivity of solutions of LiFSI and $\mathrm{LiPF}_{6}$ in $\mathrm{PC}$ as a function of the molarity of salt at a constant temperature of $298 \mathrm{~K}$. Also for that solvent, the two data sets from literature for solutions of $\mathrm{LiPF}_{6}$ $[25,46]$ are found to be contradictory. No matter which of the data sets for $\mathrm{LiPF}_{6}$ is used, the solutions of LiFSI feature a higher electrical conductivity in the entire studied range. a molar mass of only $145 \mathrm{~g} \mathrm{~mol}^{-1}$ whereas that of the $\mathrm{FSI}^{-}$-ion is $180 \mathrm{~g} \mathrm{~mol}^{-1}$. Also in terms of mobility, the bulky shape of the FSI--ion with a volume of $95 \AA^{3}$ 


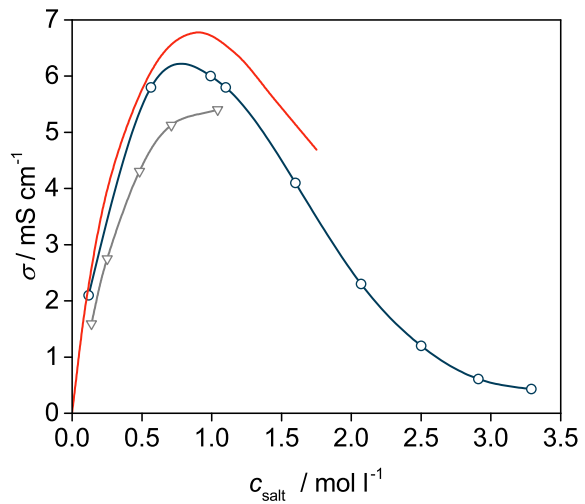

Figure 8: Electrical conductivity of solutions of LiFSI and $\mathrm{LiPF}_{6}$ in $\mathrm{PC}$ as a function of the molarity of salt for a temperature of $298.15 \mathrm{~K}$. Red line: Regression for LiFSI-PC (this work). Symbols: Experimental data for $\mathrm{LiPF}_{6}{ }^{-}$ $\mathrm{PC}$ taken from [46] (blue circle) and [25] (grey triangle) with lines as guide to the eye.

is disadvantageous compared to $\mathrm{PF}_{6}^{-}\left(69 \AA^{3}\right)$ [11]. Hence, the higher electrical conductivity of LiFSI compared to $\mathrm{LiPF}_{6}$ must stem from different interactions of the anion $\left(\mathrm{PF}_{6}^{-}, \mathrm{FSI}^{-}\right)$with the solvents and the counter-ion $\left(\mathrm{Li}^{+}\right)$. The negative charge of the $\mathrm{FSI}^{-}$-ion is delocated over the large volume, explainable by the multiple possible resonance structures. This delocation weakens the attractive interactions with the solvent as well as with the counter-ion $\mathrm{Li}^{+}$[47].

The delocation of the negative charge is much smaller for $\mathrm{PF}_{6}^{-}$than it is for $\mathrm{FSI}^{-}$, which leads to a strong binding of the solvent shell and counter-ion cloud. This effect increases the viscosity (reduced mobility of the anion), decreases the degree of dissociation and thus results in a lower electrical conductivity for solutions of $\mathrm{LiPF}_{6}$. This conclusion is also in line with a result of a comparison of the shear viscosity of solutions of LiFSI and $\mathrm{LiPF}_{6}$ in $\mathrm{PC}$ which is presented 

lower viscosity than solutions of $\mathrm{LiPF}_{6}$ in $\mathrm{PC}$ at the same molarity of salt and temperature. Also this finding supports that the interactions of the $\mathrm{FSI}^{-}$-ion in solution are weaker compared to those of the $\mathrm{PF}_{6}^{-}$-ion.

\subsection{Conclusions}

In the present work, a systematic investigation of the density, shear viscosity and electrical conductivity of solutions of LiFSI in dimethyl carbonate (DMC), ethylene carbonate (EC), and propylene carbonate (PC) was carried out at ambient pressure, temperatures between 273 and $333 \mathrm{~K}$, and mole fractions of LiFSI up to $0.45 \mathrm{~mol} \mathrm{~mol}^{-1}$. Empirical correlations are provided, which are faithful LiFSI have superior properties, with regard to the electrical conductivity and shear viscosity, as compared to solutions of $\mathrm{LiPF}_{6}$. The higher electrical conductivity and lower shear viscosity must stem from weaker attractive interactions of the $\mathrm{FSI}^{-}$-ion with the solvents and the counter-ion $\mathrm{Li}^{+}$compared to $\mathrm{PF}_{6}^{-}$. ${ }_{320}$ The findings underpin that LiFSI is a promising candidate to replace $\mathrm{LiPF}_{6}$. The data and correlations presented here provide a sound basis for the design and optimization of LiFSI-based electrolyte systems for LiB.

\section{References}

[1] B. Scrosati, J. Garche, Lithium batteries: Status, prospects and future, Journal of Power Sources $195 \quad$ (2010) 2419-2430. doi:10.1016/j.jpowsour.2009.11.048. 
[2] A. Thielmann, A. Sauer, M. Wietschel, Gesamt-Roadmap Lithium-IonenBatterien 2030, Tech. rep., Fraunhofer-Institut für System- und Innovationsforschung ISI, Karlsruhe (2015).

[3] T. Stocker, D. Qin, G.-K. Plattner, M. Tignor, S. Allen, J. Boschung, A. Nauels, Y. Xia, V. Bex, P. Midgley, IPCC, 2013: Climate Change 2013: The Physical Science Basis. Contribution of Working Group I to the Fifth Assessment Report of the Intergovernmental Panel on Climate Change, Tech. rep., Cambridge University Press, Cambridge, United Kingdom and New York, NY, USA (2013).

[4] Y. Nishi, Lithium ion secondary batteries; past 10 years and the future, Journal of Power Sources 100 (2001) 101-106.

[5] H. Ota, K. Shima, M. Ue, J.-I. Yamaki, Effect of vinylene carbonate as additive to electrolyte for lithium metal anode, Electrochimica Acta 49 (2004)565-572. doi:10.1016/j.electacta.2003.09.010.

[6] S. S. Zhang, A review on electrolyte additives for lithiumion batteries, Journal of Power Sources 162 (2006) 1379-1394. doi:10.1016/j.jpowsour.2006.07.074.

[7] G. E. Blomgren, Electrolytes for advanced batteries, Journal of Power Sources 81 (1999) 112-118.

[8] G. E. Blomgren, Liquid electrolytes for lithium and lithiumion batteries, Journal of Power Sources 119121 (2003) 326-329. doi:10.1016/s0378-7753(03)00147-2. 
[9] C. L. Berhaut, P. Porion, L. Timperman, G. Schmidt, D. Lemordant, M. Anouti, Litdi as electrolyte salt for li-ion batteries: transport properties in ec/dmc, Electrochimica Acta 180 (2015) 778 - 787. doi:https://doi.org/10.1016/j.electacta.2015.08.165.

[10] G. E. Blomgren, The Development and Future of Lithium Ion Batteries, Journal of The Electrochemical Society 164 (2017) A5019-A5025. doi:10.1149/2.0251701jes.

[11] H.-B. Han, S.-S. Zhou, D.-J. Zhang, S.-W. Feng, L.-F. Li, K. Liu, W.F. Feng, J. Nie, H. Li, X.-J. Huang, M. Armand, Z.-B. Zhou, Lithium bis(fluorosulfonyl)imide (LiFSI) as conducting salt for nonaqueous liquid electrolytes for lithium-ion batteries: Physicochemical and electrochemical properties, Journal of Power Sources 196 (2011) 3623-3632. doi:10.1016/j.jpowsour.2010.12.040.

[12] S.-D. Han, O. Borodin, D. M. Seo, Z.-B. Zhou, W. A. Henderson, Electrolyte solvation and ionic association V. Acetonitrile-lithium bis (fluorosulfonyl) imide (LiFSI) mixtures, Journal of The Electrochemical Society $365 \quad 161(2014)$ A2042-A2053.

[13] S. Lux, I. Lucas, E. Pollak, S. Passerini, M. Winter, R. Kostecki, The mechanism of HF formation in $\mathrm{LiPF}_{6}$ based organic carbonate electrolytes, Electrochemistry Communications 14 (2012) 47-50. doi:10.1016/j.elecom.2011.10.026.

[14] G. G. Eshetu, S. Grugeon, G. Gachot, D. Mathiron, M. Armand, 
S. Laruelle, LiFSI vs. $\mathrm{LiPF}_{6}$ electrolytes in contact with lithiated graphite: Comparing thermal stabilities and identification of specific SEI-reinforcing additives, Electrochimica Acta 102 (2013) 133-141. doi:10.1016/j.electacta.2013.03.171.

375 [15] C. Forestier, S. Grugeon, C. Davoisne, A. Lecocq, G. Marlair, M. Armand, L. Sannier, S. Laruelle, Graphite electrode thermal behavior and solid electrolyte interphase investigations: Role of state-of-the-art binders, carbonate additives and lithium bis(fluorosulfonyl)imide salt, Journal of Power Sources 330 (2016) 186-194. doi:10.1016/j.jpowsour.2016.09.005.

[16] J. Wang, Y. Yamada, K. Sodeyama, C. H. Chiang, Y. Tateyama, A. Yamada, Superconcentrated electrolytes for a high-voltage lithium-ion battery, Nature Communications $7 \quad$ (2016) 12032. doi:10.1038/ncomms12032. X. Huang, Transport and Electrochemical Properties and Spectral Features of Non-Aqueous Electrolytes Containing LiFSI in Linear Carbonate Solvents, Journal of The Electrochemical Society 158 (2011) A74-A82. doi:10.1149/1.3514705.

[18] J. Qian, W. A. Henderson, W. Xu, P. Bhattacharya, M. Engelhard, O. Borodin, J.-G. Zhang, High rate and stable cycling of 
lithium metal anode, Nature Communications 6 (2015) ncomms7362. doi: $10.1038 /$ ncomms 7362.

[19] T. Takekawa, K. Kamiguchi, H. Imai, M. Hatano, Physicochemical and Electrochemical Properties of the Organic Solvent Electrolyte with Lithium Bis(fluorosulfonyl)Imide (LiFSI) As Lithium-Ion Conducting Salt for Lithium-Ion Batteries, ECS Transactions 64 (24) (2015) 11-16. doi:10.1149/06424.0011ecst.

[20] S. Uchida, M. Ishikawa, Lithium bis(fluorosulfonyl)imide based low ethylene carbonate content electrolyte with unusual solvation state, Journal of Power Sources 359 (2017) 480-486. doi:10.1016/j.jpowsour.2017.05.090.

[21] M. S. Ding, Liquid-Solid Phase Equilibria and Thermodynamic Modeling for Binary Organic Carbonates, Journal of Chemical \& Engineering Data 49 (2004) 276-282. doi:10.1021/je034134e.

[22] O. Borodin, G. D. Smith, Quantum Chemistry and Molecular Dynamics Simulation Study of Dimethyl Carbonate: Ethylene Carbonate Electrolytes Doped with $\mathrm{LiPF}_{6}$, The Journal of Physical Chemistry B 113 (2009) 17631776. doi:10.1021/jp809614h.

${ }_{410}$ [23] R. Francesconi, F. Comelli, Vapor-Liquid Equilibria, Excess Molar Enthalpies, and Excess Molar Volumes of Dimethyl Carbonate + 1,2Epoxybutane at 288.15, 298.15, or 313.15 K, Journal of Chemical \& Engineering Data 41 (1996) 736-740. doi:10.1021/je950298m. 
[24] P. T. Thompson, B. Fisher, R. H. Wood, Viscosities of solutions of electrolytes and non-electrolytes in ethylene carbonate at $40{ }^{\circ} \mathrm{C}$, Journal of Solution Chemistry 11 (1982) 1-15. doi:10.1007/BF00664330.

[25] J. Barthel, H.-J. Gores, P. Carlier, F. Feuerlein, M. Utz, The Temperature Dependence of the Properties of Electrolyte Solutions. V. Determination of the Glass Transition Temperature and Comparison of the Temperature Coefficients of Electrolyte Conductance and Solvent Viscosity of Propylene Carbonate Solutions, Berichte der Bunsengesellschaft für physikalische Chemie 87 (1983) 436-443. doi:10.1002/bbpc.19830870516.

[26] A. Rodríguez, A. B. Pereiro, J. Canosa, J. Tojo, Dynamic viscosities of the ternary liquid mixtures (dimethyl carbonate + methanol + ethanol) ${ }_{425}$ and (dimethyl carbonate + methanol + hexane) at several temperatures, The Journal of Chemical Thermodynamics 38 (2006) 505-519. doi:10.1016/j.jet.2005.07.008.

[27] S.-I. Tobishima, K. Hayashi, K.-I. Saito, J.-I. Yamaki, Ethylene carbonate-based ternary mixed solvent electrolytes for rechargeable lithium batteries, Electrochimica Acta 40 (1995) 537-544. doi:10.1016/0013-4686(95)00004-X.

[28] K. Hayamizu, Y. Aihara, S. Arai, C. G. Martinez, Pulse-Gradient SpinEcho ${ }^{1} \mathrm{H},{ }^{7} \mathrm{Li}$, and ${ }^{19} \mathrm{~F}$ NMR Diffusion and Ionic Conductivity Measurements of 14 Organic Electrolytes Containing $\mathrm{LiN}\left(\mathrm{SO}_{2} \mathrm{CF}_{3}\right)_{2}$, The Journal of Physical Chemistry B 103 (1999) 519-524. doi:10.1021/jp9825664. 
[29] N. Nanbu, M. Takehara, S. Watanabe, M. Ue, Y. Sasaki, Polar Effect of Successive Fluorination of Dimethyl Carbonate on Physical Properties, Bulletin of the Chemical Society of Japan 80 (2007) 1302-1306.

[30] R. Payne, I. E. Theodorou, Dielectric properties and relaxation in ethylene carbonate and propylene carbonate, The Journal of Physical Chemistry 76 (1972) 2892-2900.

[31] K. Xu, Nonaqueous Liquid Electrolytes for Lithium-Based Rechargeable Batteries, Chemical Reviews 104 (2004) 4303-4418. doi:10.1021/cr030203g.

[32] J. C. Wadsworth, The Statistical Description of Precision Conductivity Data for Aqueous Sodium Chloride, Journal of Solution Chemistry 41 (2012) 715-729. doi:10.1007/s10953-012-9823-6.

[33] S. Reiser, M. Horsch, H. Hasse, Temperature Dependence of the Density of Aqueous Alkali Halide Salt Solutions by Experiment and Molecular Simulation, Journal of Chemical \& Engineering Data 59 (2014) 3434-3448. doi:10.1021/je500420g.

[34] S. Reiser, M. Horsch, H. Hasse, Density of Methanolic Alkali Halide Salt Solutions by Experiment and Molecular Simulation, Journal of Chemical \& Engineering Data 60 (2015) 1614-1628. doi:10.1021/je5009944.

${ }_{455}$ [35] S.-A. Hyodo, K. Okabayashi, Raman intensity study of local structure in non-aqueous electrolyte solutionsI. Cation-solvent interaction in $\mathrm{LiClO}_{4}$ /ethylene carbonate, Electrochimica acta 34 (1989) 1551-1556. 
[36] O. Borodin, M. Olguin, P. Ganesh, P. R. C. Kent, J. L. Allen, W. A. Henderson, Competitive lithium solvation of linear and cyclic carbonates from quantum chemistry, Phys. Chem. Chem. Phys. 18 (2016) 164-175. doi:10.1039/C5CP05121E.

[37] Y. Kameda, Y. Umebayashi, M. Takeuchi, M. A. Wahab, S. Fukuda, S.-I. Ishiguro, M. Sasaki, Y. Amo, T. Usuki, Solvation Structure of $\mathrm{Li}^{+}$in Concentrated $\mathrm{LiPF}_{6}$ Propylene Carbonate Solutions, The Journal of Physical Chemistry B 111 (2007) 6104-6109. doi:10.1021/jp072597b.

[38] M. Masia, M. Probst, R. Rey, Ethylene Carbonate-Li ${ }^{+}$: A Theoretical Study of Structural and Vibrational Properties in Gas and Liquid Phases, The Journal of Physical Chemistry B 108 (2004) 2016-2027. doi:10.1021/jp036673w.

[39] J.-C. Soetens, C. Millot, B. Maigret, Molecular Dynamics Simulation of $\mathrm{Li}^{+} \mathrm{BF}_{4}^{-}$in Ethylene Carbonate, Propylene Carbonate, and Dimethyl Carbonate Solvents, The Journal of Physical Chemistry A 102 (1998) 10551061.

[40] Y. Wang, P. B. Balbuena, Associations of Alkyl Carbonates: Intermolecular 475 CHO Interactions, The Journal of Physical Chemistry A 105 (2001) 99729982. doi:10.1021/jp0126614.

[41] L. B. Silva, L. C. G. Freitas, Structural and thermodynamic properties of liquid ethylene carbonate and propylene carbonate by Monte Carlo Simu- 
lations, Journal of Molecular Structure: THEOCHEM 806 (2007) 23-34.

[42] J. Arai, K. Nishimura, Y. Muranaka, Y. Ito, Characterization of organic electrolyte systems by nuclear magnetic resonance and molecular orbital simulation: equilibrium constant and net charge distribution in solvation state, Journal of power sources 68 (2) (1997) 304-306.

[43] R. Meier, Neue nichtwässrige Elektrolyte für technische Anwendungen: Charakterisierung ihres Leitfähigkeitsverhaltens in Abhängigkeit von Konzentration, Temperatur und Zusammensetzung der Mischlösungsmittel., Ph.D. thesis, Regensburg, Univ., Naturwiss. Fak. IVChemie und Pharmazie, Diss. (1998).

[44] Y. Sasaki, M. Takehara, S. Watanabe, N. Nanbu, M. Ue, Physical and electrolytic properties of difluorinated dimethyl carbonate, Journal of Fluorine Chemistry 125 (2004) 1205-1209. doi:10.1016/j.jfluchem.2004.05.008.

[45] M. Ue, Y. Sasaki, Y. Tanaka, M. Morita, Nonaqueous Electrolytes with Advances in Solvents, in: T. R. Jow, K. Xu, O. Borodin, M. Ue (Eds.), Electrolytes for Lithium and Lithium-Ion Batteries, Modern Aspects of Electrochemistry, Springer New York, 2014, pp. 93-165. doi:10.1007/978-1-4939-0302-3\_2.

[46] K. Kondo, M. Sano, A. Hiwara, T. Omi, M. Fujita, A. Kuwae, M. Iida, K. Mogi, H. Yokoyama, Conductivity and Solvation of $\mathrm{Li}^{+}$Ions of $\mathrm{LiPF}_{6}$ 
in Propylene Carbonate Solutions, Journal of Physical Chemistry B 104 (2000) 5040-5044.

[47] I. Krossing, I. Raabe, Noncoordinating Anions - Fact or Fiction? A Survey of Likely Candidates, Angewandte Chemie International Edition 43 (2004) 2066-2090. doi:10.1002/anie.200300620.

\section{Appendix A. Experimental data}

Tables A1, A2, and A3 list the experimental data of the density of solutions of LiFSI in DMC, EC, and PC. The experimental data of the shear viscosity of solutions of LiFSI in DMC, EC, and PC are given in Tables A4, A5, and A6. Tables A7, A8, and A9 present the experimental data of the electrical conductivity of solutions of LiFSI in DMC, EC, and PC. All experiments were carried out at ambient pressure. Uncertainties are discussed in the text.

Table A1: Experimental data of the density of solutions of LiFSI in DMC.

\begin{tabular}{ccccc}
\hline \hline$x_{\text {LiFSI }} / \mathrm{mol} \mathrm{mol}^{-1}$ & \multicolumn{4}{c}{$\rho / \mathrm{g} \mathrm{cm}^{-3}$} \\
\hline & $283.15 \mathrm{~K}$ & $293.15 \mathrm{~K}$ & $313.15 \mathrm{~K}$ & $333.15 \mathrm{~K}$ \\
\hline 0.0000 & 1.0827 & 1.0697 & 1.0432 & 1.0162 \\
0.1027 & 1.2105 & 1.1981 & 1.1735 & 1.1480 \\
0.2001 & 1.3250 & 1.3132 & 1.2898 & 1.2663 \\
0.2502 & 1.3759 & 1.3644 & 1.3415 & 1.3185 \\
0.3001 & 1.4239 & 1.4128 & 1.3907 & 1.3687 \\
0.3500 & 1.4700 & 1.4592 & 1.4375 & 1.4159 \\
0.3999 & 1.5165 & 1.5069 & 1.4850 & 1.4632 \\
0.4493 & 1.5634 & 1.5527 & 1.5313 & 1.5103 \\
\hline \hline
\end{tabular}


Table A2: Experimental data of the density of solutions of LiFSI in EC.

\begin{tabular}{c|c|c|c|c}
\hline \hline & \multicolumn{4}{|c}{$\rho / \mathrm{g} \mathrm{cm}^{-3}$} \\
\hline $\begin{array}{c}x_{\text {LiFSI }} / \\
\text { mol mol }^{-1}\end{array}$ & 303.15 & 313.15 & 323.15 & 333.15 \\
\hline 0.0000 & - & 1.3200 & 1.3052 & 1.2938 \\
0.0501 & 1.3837 & 1.3734 & 1.3621 & 1.3510 \\
0.1004 & 1.4382 & 1.4237 & 1.4126 & 1.4048 \\
0.2000 & 1.5253 & 1.5144 & 1.5034 & 1.4921 \\
0.2500 & 1.5656 & 1.5543 & 1.5446 & 1.5340 \\
0.3000 & 1.6040 & 1.5934 & 1.5828 & 1.5723 \\
0.3500 & 1.6415 & 1.6308 & 1.6202 & 1.6098 \\
0.4001 & 1.6799 & 1.6689 & 1.6580 & 1.6551 \\
0.4500 & 1.7165 & 1.7048 & 1.6938 & 1.6832 \\
\hline \hline
\end{tabular}

Table A3: Experimental data of the density of solutions of LiFSI in PC.

\begin{tabular}{c|c|c|c|c}
\hline \hline & \multicolumn{4}{|c}{$\rho / \mathrm{g} \mathrm{cm}^{-3}$} \\
\hline$x_{\text {LiFSI }} /$ & \multicolumn{4}{|c}{$T / \mathrm{K}$} \\
$\mathrm{mol} \mathrm{mol}^{-1}$ & 273.15 & 293.15 & 313.15 & 333.15 \\
\hline 0.0000 & 1.2262 & 1.2048 & 1.1835 & 1.1623 \\
0.1000 & 1.3229 & 1.3017 & 1.2808 & 1.2601 \\
0.2000 & 1.4135 & 1.3927 & 1.3719 & 1.3516 \\
0.2500 & 1.4559 & 1.4359 & 1.4153 & 1.3934 \\
0.2996 & 1.4983 & 1.4770 & 1.4567 & 1.4367 \\
0.3501 & 1.5418 & 1.5198 & 1.4991 & 1.4791 \\
0.4000 & 1.5851 & 1.5629 & 1.5414 & 1.5211 \\
0.4488 & 1.6279 & 1.6040 & 1.5830 & 1.5623 \\
\hline \hline
\end{tabular}

Table A4: Experimental data of the shear viscosity of solutions of LiFSI in DMC.

\begin{tabular}{c|c|c|c|c}
\hline \hline & \multicolumn{4}{|c}{$\eta / \mathrm{mPa} \mathrm{s}$} \\
\hline$x_{\text {LiFSI }} /$ & \multicolumn{4}{|c}{$T / \mathrm{K}$} \\
mol mol $^{-1}$ & 283.15 & 293.15 & 313.15 & 333.15 \\
\hline 0.0000 & 0.828 & 0.730 & 0.581 & 0.455 \\
0.1027 & 2.567 & 2.099 & 1.483 & 1.112 \\
0.2001 & 10.571 & 7.769 & 4.664 & 3.163 \\
0.2502 & 22.539 & 15.408 & 8.444 & 5.344 \\
0.3001 & 47.954 & 27.250 & 15.285 & 9.027 \\
0.3500 & 101.830 & 60.679 & 27.250 & 14.951 \\
0.3999 & 228.600 & 129.170 & 50.214 & 25.119 \\
0.4493 & 560.810 & 279.240 & 95.880 & 43.863 \\
\hline \hline
\end{tabular}


Table A5: Experimental data of the shear viscosity of solutions of LiFSI in EC.

\begin{tabular}{c|c|c|c|c}
\hline \hline & \multicolumn{4}{|c}{$\eta / \mathrm{mPa} \mathrm{s}$} \\
\hline $\begin{array}{c}x_{\mathrm{LiFSI}} / \\
\mathrm{mol} \mathrm{mol}^{-1}\end{array}$ & 303.15 & 313.15 & 323.15 & 333.15 \\
\hline 0.0000 & - & 1.900 & 1.595 & 1.387 \\
0.0501 & 4.428 & 3.659 & 2.996 & 2.537 \\
0.1004 & 9.715 & 7.086 & 5.610 & 4.740 \\
0.2000 & 47.269 & 30.605 & 21.148 & 15.290 \\
0.2500 & 94.365 & 56.674 & 37.692 & 26.166 \\
0.3000 & 162.470 & 93.946 & 59.116 & 39.634 \\
0.3500 & 261.850 & 145.370 & 88.380 & 57.895 \\
0.4001 & 431.460 & 229.940 & 133.770 & 92.133 \\
0.4500 & 742.160 & 370.310 & 206.980 & 126.280 \\
\hline \hline
\end{tabular}

Table A6: Experimental data of the shear viscosity of solutions of LiFSI in PC.

\begin{tabular}{|c|c|c|c|c|}
\hline & \multicolumn{4}{|c|}{$\eta / \mathrm{mPas}$} \\
\hline$x_{\text {LiFSI }} /$ & \multicolumn{4}{|c|}{$T / \mathrm{K}$} \\
\hline $\mathrm{mol} \mathrm{mol}^{-1}$ & 273.15 & 293.15 & 313.15 & 333.15 \\
\hline 0.0000 & 4.635 & 2.841 & 1.950 & 1.467 \\
\hline 0.1000 & 23.269 & 10.999 & 6.336 & 4.120 \\
\hline 0.2000 & 187.280 & 57.095 & 24.616 & 13.090 \\
\hline 0.2500 & 467.030 & 120.600 & 45.689 & 21.766 \\
\hline 0.2996 & 948.193 & 217.080 & 75.211 & 34.387 \\
\hline 0.3501 & 1875.100 & 370.580 & 118.260 & 50.891 \\
\hline 0.4000 & 3770.700 & 639.650 & 185.770 & 74.466 \\
\hline 0.4488 & 8162.500 & 1129.000 & 296.470 & 110.460 \\
\hline
\end{tabular}


Table A7: Experimental data of the electrical conductivity of solutions of LiFSI in DMC.

\begin{tabular}{c|c|c|c|c|c|c}
\hline \hline & \multicolumn{7}{|c}{$\sigma / \mathrm{mS} \mathrm{cm}^{-1}$} \\
\hline $\begin{array}{c}x_{\text {LiFSI }} / \\
\text { mol mol }^{-1}\end{array}$ & 283.15 & 293.15 & 303.15 & 313.15 & 323.15 & 333.15 \\
\hline 0.0000 & 0.00 & 0.00 & 0.00 & 0.00 & 0.00 & 0.00 \\
0.0100 & 0.01 & 0.07 & 0.08 & 0.09 & 0.10 & 0.10 \\
0.0340 & 1.89 & 2.11 & 2.32 & 2.53 & 2.71 & 2.89 \\
0.0499 & 3.58 & 4.03 & 4.46 & 4.88 & 5.22 & 5.58 \\
0.0749 & 6.05 & 6.87 & 7.66 & 8.41 & 9.09 & 9.86 \\
0.0999 & 7.70 & 8.90 & 10.00 & 11.11 & 12.17 & 13.19 \\
0.1249 & 8.40 & 9.83 & 11.24 & 12.61 & 13.98 & 15.27 \\
0.1500 & 8.25 & 9.89 & 11.50 & 13.12 & 14.64 & 16.19 \\
0.1706 & 7.71 & 9.39 & 11.10 & 12.84 & 14.58 & 16.20 \\
0.2000 & 6.69 & 8.38 & 10.02 & 11.69 & 13.47 & 15.33 \\
\hline \hline
\end{tabular}

Table A8: Experimental data of the electrical conductivity of solutions of LiFSI in EC.

\begin{tabular}{c|c|c|c}
\hline \hline & \multicolumn{3}{|c}{$\sigma / \mathrm{mS} \mathrm{cm}^{-1}$} \\
\hline$x_{\text {LiFSI }} /$ & \multicolumn{3}{|c}{$T / \mathrm{K}$} \\
mol mol $^{-1}$ & 313.15 & 323.15 & 333.15 \\
\hline 0.0000 & 0.01 & 0.02 & 0.02 \\
0.0114 & 2.98 & 3.43 & 3.89 \\
0.0248 & 5.52 & 6.38 & 7.58 \\
0.0503 & 8.75 & 10.22 & 11.73 \\
0.0745 & 10.52 & 12.32 & 14.21 \\
0.0994 & 11.15 & 13.27 & 15.45 \\
0.1259 & 10.84 & 13.13 & 15.52 \\
0.1493 & 9.70 & 12.01 & 14.60 \\
0.1753 & 6.34 & 8.32 & 10.54 \\
\hline \hline
\end{tabular}


Table A9: Experimental data of the electrical conductivity of solutions of LiFSI in $\mathrm{PC}$.

\begin{tabular}{c|c|c|c|c|c|c|c}
\hline \hline & \multicolumn{7}{c}{$\sigma / \mathrm{mS} \mathrm{cm}^{-1}$} \\
\hline $\begin{array}{c}x_{\mathrm{LiFSI}} / \\
\mathrm{mol} \mathrm{mol}^{-1}\end{array}$ & 273.15 & 283.15 & 293.15 & 303.15 & 313.15 & 323.15 & 333.15 \\
\hline 0.0000 & 0.00 & 0.00 & 0.00 & 0.00 & 0.00 & 0.00 & 0.00 \\
0.0100 & 1.27 & 1.63 & 2.01 & 2.42 & 2.86 & 3.31 & 3.76 \\
0.0251 & 2.41 & 3.13 & 3.85 & 4.68 & 5.53 & 6.44 & 7.37 \\
0.0499 & 3.16 & 4.26 & 5.44 & 6.71 & 8.05 & 9.42 & 10.82 \\
0.0750 & 3.28 & 4.52 & 5.81 & 7.27 & 8.84 & 10.54 & 12.28 \\
0.1000 & 2.80 & 4.00 & 5.39 & 6.91 & 8.59 & 10.30 & 12.21 \\
0.1249 & 1.92 & 3.25 & 4.52 & 6.04 & 7.77 & 9.56 & 11.49 \\
0.1499 & 1.54 & 2.54 & 3.71 & 5.04 & 6.60 & 8.29 & 10.18 \\
0.1746 & 1.26 & 2.07 & 3.13 & 4.21 & 5.47 & 7.32 & 9.04 \\
\hline \hline
\end{tabular}

Table B2: Parameters of the correlation function (Eq. (6)) for the shear viscosity in the systems LiFSI-DMC, LiFSI-EC, and LiFSI-PC.

\begin{tabular}{cccc}
\hline \hline & LiFSI-DMC & LiFSI-EC & LiFSI-PC \\
\hline$a_{0, k}$ & -4.09 & -4.65 & -5.13 \\
$b_{0, k}$ & 4.05 & 6.06 & 6.66 \\
$a_{1, k}$ & -2.08 & 132.24 & 25.95 \\
$b_{1, k}$ & 15.85 & -306.97 & -59.09 \\
$c_{1, k}$ & -2.61 & 197.74 & 51.71 \\
$a_{2, k}$ & 88.00 & -9.88 & 69.96 \\
$b_{2, k}$ & -229.49 & 2.95 & -173.59 \\
$c_{2, k}$ & 152.22 & - & 99.36 \\
\hline \hline
\end{tabular}




\section{Appendix B. Correlation parameters}

Tables B1, B2, and B3 list the parameters of the empirical correlations for

515

work.

Table B1: Parameters of the correlation function (Eq. (1)) for the density in the systems LiFSI-DMC, LiFSI-EC, and LiFSI-PC.

\begin{tabular}{cccc}
\hline \hline & LiFSI-DMC & LiFSI-EC & LiFSI-PC \\
\hline$a_{0, k}$ & 1.4596 & 1.7297 & 1.5170 \\
$b_{0, k}$ & -0.3634 & -0.3578 & -0.2909 \\
$a_{1, k}$ & 1.0216 & 0.3424 & 0.7815 \\
$b_{1, k}$ & 0.2792 & 0.6464 & 0.1374 \\
$a_{2, k}$ & 0.8595 & 1.9822 & 1.6611 \\
$b_{2, k}$ & -0.1111 & -1.3014 & -0.4822 \\
\hline \hline
\end{tabular}

Table B3: Parameters of the correlation function (Eq. (8)) for the electrical conductivity in the systems LiFSI-DMC, LiFSI-EC, and LiFSI-PC.

\begin{tabular}{cccc}
\hline \hline & LiFSI-DMC & LiFSI-EC & LiFSI-PC \\
\hline$a_{0, k}$ & -0.000039 & -0.045766 & -0.013769 \\
$b_{0, k}$ & 0.000036 & 0.051352 & 0.014345 \\
$a_{1, k}$ & 39696.70 & -277502.46 & -119644.03 \\
$b_{1, k}$ & -66030.37 & 274159.77 & 139370.77 \\
$a_{2, k}$ & -97397.55 & 720691.16 & 297508.37 \\
$b_{2, k}$ & 165890.90 & -709875.76 & -346118.91 \\
$a_{3, k}$ & 78778.42 & -626223.45 & -248376.20 \\
$b_{3, k}$ & -137737.09 & 615333.70 & 288357.34 \\
$a_{4, k}$ & -21099.24 & 181778.11 & 69510.32 \\
$b_{4, k}$ & 37923.42 & -178283.82 & -80484.08 \\
\hline \hline
\end{tabular}




\section{Supplementary Information}




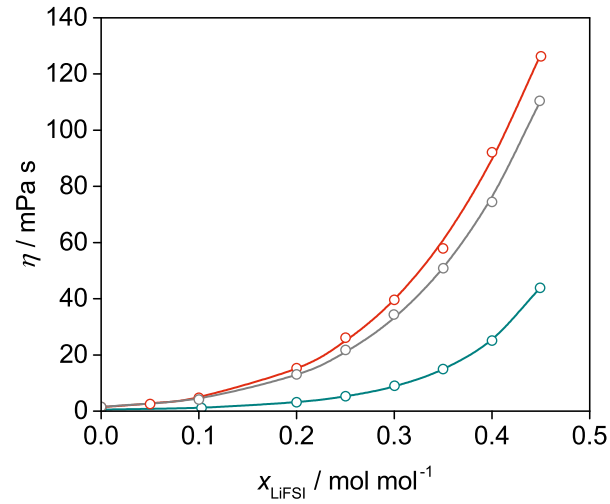

Figure S1: Shear viscosity of solutions of LiFSI in a) DMC (blue), b) EC (red), and c) PC (grey) as a function of the mole fraction of LiFSI at $333 \mathrm{~K}$. Symbols: experimental data. Lines: correlations fitted to the experimental data, cf. Eq. (6).

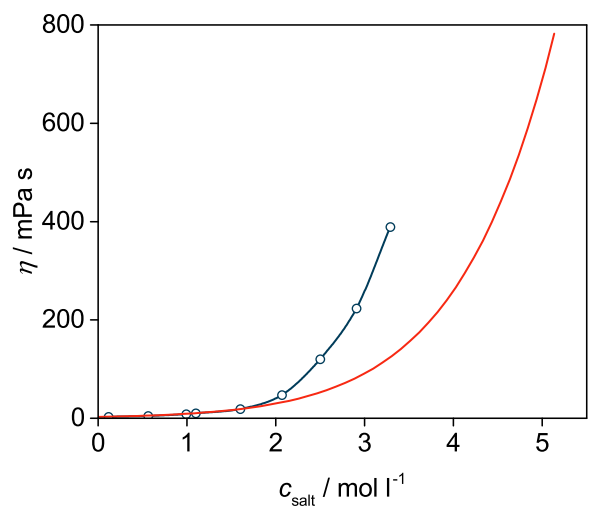

Figure S2: Shear viscosity of solutions of LiFSI and $\mathrm{LiPF}_{6}$ in $\mathrm{PC}$ as a function of the molarity of salt for a temperature of $298.15 \mathrm{~K}$. Red line: Regression for LiFSI-PC (this work). Symbols: Experimental data for $\mathrm{LiPF}_{6}-\mathrm{PC}$ taken from [46] (blue) with line as guide to the eye. 